\title{
Hubungan Faktor Water, Sanitation, and Hygiene (WASH) dengan Stunting di Wilayah Kerja Puskesmas Kotakulon, Kabupaten Bondowoso
}

\author{
The Assosiation of Water, Sanitation, and Hygiene (WASH) factor with \\ Stunting in Working Area of Puskesmas Kotakulon, Bondowoso District
}

\author{
Alfadhila Khairil Sinatrya*1, Lailatul Muniroh²
}

\begin{abstract}
ABSTRAK
Latar Belakang: Pada tahun 2017, prevalensi stunting di Indonesia mencapai angka 29,6\% dan Kabupaten Bondowoso adalah kabupaten yang menyumbang angka tertinggi ketiga di Jawa Timur yaitu sebesar $38,3 \%$ balita stunting. Salah satu penyebab tidak langsung dari stunting adalah faktor water, sanitation, and hygiene (WASH).

Tujuan: Penelitian ini bertujuan untuk enganalisis hubungan WASH dengan stunting pada anak usia $24-59$ bulan di Wilayah Kerja Puskesmas Kotakulon, Kabupaten Bondowoso.

Metode: Jenis penelitian adalah observasional analitik dengan desain kasus kontrol. Besar sampel penelitian yaitu 66 balita usia 24 - 59 bulan di wilayah kerja Puskesmas Kotakulon, Kabupaten Bondowoso. Penelitian kasus kontrol ini terdiri dari sampel kasus sebanyak 33 balita yang mengalami stunting dan sampel kontrol sebanyak 33 balita yang tidak mengalami stunting. Variabel dependen adalah kejadian stunting. Variabel independen adalah WASH, meliputi sumber air minum, kualitas fisik air minum, kepemilikan jamban, dan kebiasaan cuci tangan ibu. Data dianalisis menggunakan uji chi-square. Hasil: Kebiasaan cuci tangan $(p<0,001 ; O R=0,12$ ) adalah faktor risiko dari stunting pada balita dengan besar risiko 0,12 kali lebih tinggi bagi ibu yang memiliki kebiasaan cuci tangan kurang baik, sedangkan sumber air minum $(p=0,415)$, kualitas fisik air minum $(p=0,58)$, kepemilikan jamban $(p=0,22)$ bukan merupakan faktor risiko dari stunting.

Kesimpulan: Kebiasaan cuci tangan yang buruk pada ibu berkontribusi terhadap kejadian stunting di wilayah kerja Puskesmas Kotakulon Kabupaten Bondowoso.
\end{abstract}

Kata kunci: balita, stunting, WASH, Bondowoso

\section{ABSTRACT}

Background: In 2017 prevalence of stunting in, Indonesia reached 29.6\% and Bondowoso District was one of district that contributes the third higher prevalence, amounted 38.3\%. One of underlying cause of stunting were water, sanitation and hygiene (WASH).

Objectives: This research aims to analyze the correlation between WASH with stunting among children aged 24 - 59 months in working area of Kotakulon Public Health Center, Bondowoso District.

Methods: This was an observational analytic study with case-control design. The sample size of this research was 66 children aged 24 to 59 months in working area of Kotakulon Public Health Center, Bondowoso District. This case-control study consisted of 33 children in case group and 33 children sample of contro groupl. The dependent variable was stunting status, while the independent variables were drinking water source, quality of drinking water, the ownership of lathrines, and mother's handwashing habits. The data were analyzed using chi-square test.

Results: Hand washing habit ( $p<0.001 ; 0 R=0.12$ ) was a risk factor of stunting in under-five years old which has risk 0.12 times higher for mother that has a poor handwashing habit, while drinking water source $(p=0.41)$, quality of drinking source $(p=0.58)$, the ownership of lathrines $(p=0.22)$ were not accunted as a risk of stunting.

Conclusions: A poor handwashing habit in mother contribute to stunting in working area of Kotakulon Public Health Center, Bondowoso District.

Keywords: under-five year old children, stunting, WASH, Bondowoso

\footnotetext{
*Koresponden:

aksinatrya495@gmail.com

1,2Departemen Gizi Kesehatan, Fakultas Kesehatan Masyarakat, Universitas Airlangga, Kampus C Mulyorejo 66115, Surabaya, Jawa Timur, Indonesia
} 


\section{PENDAHULUAN}

Stunting merupakan salah satu masalah gizi di masyarakat utamanya pada balita. Stunting diukur menggunakan indeks Panjang Badan menurut Umur (PB/U) atau Tinggi Badan menurut Umur (TB/U) yang dapat dikategorikan stunted (pendek) atau severely stunted (sangat pendek) ${ }^{1}$. Balita dikatakan stunting apabila Z-score tinggi badan menurut umurnya berada dibawah garis normal yaitu kurang dari -2SD dikatakan pendek dan kurang dari -3SD dikategorikan sangat pendek ${ }^{2}$.

Kabupaten Bondowoso pernah masuk dalam 100 kabupaten/kota prioritas untuk intervensi anak kerdil (stunting) yang disahkan oleh Wakil Presiden Republik Indonesia, M. Jusuf Kalla pada tahun 2017 dengan tertinggi di provinsi Jawa Timur yaitu sebanyak 56,8\% balita $^{3}$. Sejak tahun 2015 hingga 2017, Indonesia memang mengalami fluktuasi angka balita stunting usia 0 - 59 bulan yaitu 29\%, 27,5\% dan naik kembali sebesar $29,6 \% 4,5,6$. Di Propinsi Jawa Timur, prevalensi anak balita pendek mencapai angka 26,7\% dengan angka tertinggi pada Kabupaten Bangkalan yaitu sebesar $43,0 \%$, diikuti Kabupaten Pamekasan sebesar $42,5 \%$ dan Kabupaten Bondowoso yaitu $38,3 \%{ }^{6}$. Belum adanya penelitian tentang stunting yang mendasari peneliti untuk perlu melakukan penelitian di Wilayah Kerja Puskesmas Kotakulon Kabupaten Bondowoso ini.

Stunting dapat terjadi karena faktor langsung maupun tidak langsung. Faktor langsung stunting adalah nutrisi ibu saat hamil, penyakit infeksi, dan nutrisi balita sendiri, sedangkan untuk faktor tidak langsung dapat terjadi dari berbagai aspek7. Salah satu faktor tidak langsung penyebab stunting adalah water, sanitation and hygiene (WASH), yang terdiri dari sumber air minum, kualitas fisik air minum, kepemilikan jamban ${ }^{8}$ dan hygiene yaitu kebiasaan cuci tangan ${ }^{9}$. WASH mempengaruhi status gizi stunting pada balita yaitu melalui penyakit infeksi yang dialami ${ }^{7}$. Contohnya adalah kejadian diare yang menimpa balita. Kasus diare sebesar $88 \%$ disebabkan karena sumber air minum yang kurang baik, sanitasi yang tidak sesuai dan hygiene yang buruk $^{10}$. Pada tahun 2015, dari 765,094 jiwa dilaporkan hanya 411,173 (53,74\%) penduduk di Kabupaten Bondowoso yang menggunakan air minum yang layak ${ }^{11}$. Begitu pula pada tahun 2017, hanya $56,16 \%$ dari total penduduk di Kabupaten Bondowoso yang menggunakan air minum layak untuk diikonsumsi ${ }^{12}$. Balita yang berasal dari keluarga dengan air minum yang berasal dari sumber air tidak terlindung memiliki risiko 1,35 kali lebih besar untuk menjadi stunting ${ }^{13}$

Sumber air minum tidak lepas dari kualitas fisik air minum. Berdasarkan Peraturan Menteri Kesehatan Republik Indonesia No.492/MENKES/PER/IV/2010 tentang persyaratan kualitas air minum, air minum yang aman bagi kesehatan apabila memenuhi persyaratan fisika, mikrobiologi, kimiawi dan radioaktif. Parameter yang digunakan untuk melihat kualitas fisik air yang baik yaitu memenuhi syarat tidak keruh tidak berasa, tidak berbau dan tidak berwarna ${ }^{14}$. Penelitian sebelumya oleh Sukoco dkk, menyatakan bahwa lebih banyak 52,6\% balita stunting dengan kualitas fisik air yang buruk menurut persyaratan kesehatan kualitas air minum yang ditetapkan Kemenkes ${ }^{15}$.

Sanitasi yang buruk juga merupakan faktor yang dapat menyebabkan stunting terkait dengan kemungkinan munculnya penyakit infeksi. Jamban sehat adalah sarana pembuangan feses yang baik untuk menghentikan mata rantai penyebaran penyakit. Jamban yang memenuhi persyaratan kesehatan tidak menyebabkan terjadinya penyebaran langsung akibat kotoran manusia dan dapat mencegah vector pembawa penyakit pada pengguna jamban maupun lingkungan sekitarnya ${ }^{16}$. Sebuah penelitian di Sidoarjo menjelaskan bahwa ada hubungan antara penerapan jamban sehat dengan kejadian diare $(p=0,014)$ mengingat diare merupakan faktor risiko dan berkontribusi dalam kejadian stunting ${ }^{17}$.

Faktor hygiene yaitu kebiasaan cuci tangan juga merupakan faktor risiko stunting pada tingkat rumah tangga. Mencuci tangan dengan sabun adalah suatu aktivitas higiene yaitu kegiatan membersihkan tangan dengan air mengalir dan sabun agar bersih dan dapat memutus mata rantai kuman. Kementerian Kesehatan RI telah menetapkan waktu penting untuk cuci tangan pakai sabun sehingga menjadi kebiasaan, yaitu sebelum makan, sebelum mengolah dan menghidangkan makanan, sebelum menyusui, sebelum memberi makan bayi/balita, sehabis buang air besar/kecil, setelah kontak dengan hewan ${ }^{18}$. Penelitian yang dilakukan di Kabupaten Jeneponto menyatakan bahwa ibu dengan kebiasaan cuci tangan yang baik lebih rendah $16,7 \%$ risikonya untuk mengalami stunting pada balitanya. Pada penelitian tersebut, pengasuh yang tidak mencuci tangan dengan sabun merupakan faktor risiko kejadian stunting ${ }^{9}$.

Penelitian ini bertujuan untuk menganalisis hubungan antara sumber air minum, kualitas fisik air minum, kepemilikan jamban, dan kebiasaan cuci tangan dengan kejadian stunting di wilayah kerja Puskesmas Kotakulon Kabupaten Bondowoso.

\section{METODE}

Penelitian ini adalah penelitian observasional analitik dengan desain case-control dengan populasi balita berusia 24 hingga 59 bulan yang diasuh oleh ibu yang tinggal di wilayah kerja Puskesmas Kotakulon Kabupaten Bondowoso. Berdasarkan data bulan timbang Puskesmas Kotakulon pada Februari tahun 2018, populasi balita tercatat sebanyak 1570 , dengan balita stunting sebayak 69 balita dan balita non stunting sebanyak 1501. Metode simple random sampling digunakan dalam pengambilan sampel dan diperoleh besar sampel 66 balita, yaitu 33 pada kelompok kasus dan 33 balita pada kelompok kontrol.

Pengelompokkan sampel didasarkan pada zscore $\mathrm{PB} / \mathrm{U}$ atau $\mathrm{TB} / \mathrm{U}$. Kelompok kasus adalah balita dengan status gizi stunting yang ditandai dengan $z$ score $<-3 S D$ - <-2SD. Kelompok kontrol adalah balita normal yang ditandai dengan $z$-score $\geq-2 S D$ - 2SD. Pengukuran tinggi badan dilakukan dengan menggunakan microtoise.

Teknik pengumpulan data yaitu menggunakan kuesioner sanitasi yang dimodifikasi dari penelitian 
sebelumnya di Kabupaten Boyolali dan kuesioner cuci tangan dari sebuah penelitian di Bantul dengan cara wawancara ${ }^{19,20}$. Sumber air bersih yang digunakan untuk minum dikategorikan menjadi air terlindung (PDAM, air mineral dalam kemasan/air isi ulang) dan air tidak terlindung (sungai, sumur, penampungan air hujan). Kualitas fisik air minum dikategorikan menjadi dua yaitu memenuhi syarat (tidak keruh, tidak berwarna, tidak berbau dan tidak berasa) dan tidak memenuhi syarat (keruh, berwarna, berbau dan berasa) menurut penampakan fisik air minum.

Kepemilikan jamban dikategorikan menjadi memiliki jamban sehat dan tidak memiliki jamban sehat. Jamban yang sehat memiliki bangunan atas yang melindungi pengguna jamban, bangunan tengah dengan konstruksi leher angsa atau lubang tanpa leher angsa dan tertutup, lantai jamban tidak licin dan ada saluran untuk pembuangan limbah, serta memiliki bangunan bawah yang terdiri dari tangki septik atau cubluk untuk pembuangan limbah. Dikatakan tidak memiliki jamban sehat jika bangunan atas jamban tidak melindungi penggunanya, tidak terdiri dari konstruksi leher angsa atau tidak tertutup, lantai licin dan tidak terdapat saluran pebuangan limbah, serta bangunan bawah tidak terdapat pembuangan limbah seperti tangki septik atau cubluk. Jika salah satu syarat saja tidak terpenuhi maka dinyatakan tidak memiliki jamban sehat.

Kebiasaan cuci tangan dikategorikan menjadi dua yaitu baik (menggunakan air mengalir, sabun, dilakukan pada waktu yang dianjurkan) dan kurang baik (tidak menggunakan air mengalir, sabun dan tidak dilakukan dalam waktu yang dianjurkan). Apabila salah satu syarat tidak terpenuhi maka dikategorikan kebiasaan cuci tangan responden kurang baik.

Data disajikan menggunakan tabel frekuensi dan tabulasi silang antara stunting dengan sumber air minum, kualitas fisik air minum, kepemilikan jamban dan kebiasaan cuci tangan. Data dianalisis menggunakan software SPSS 21 dengan uji chi-square $(\alpha=0,05)$. Penelitian ini telah laik etik oleh Komisi Etik Fakultas Keperawatan Universitas Airlangga Surabaya dengan nomor: 1165-KEPK tanggal 31 Agustus 2018.

\section{HASIL DAN PEMBAHASAN}

Dalam penelitian ini disajikan distribusi karakteristik responden meliputi usia ibu, usia balita dan jenis kelamin balita. Selain itu juga disajikan frekuensi dan tabulasi silang antara sumber air minum, kualitas fisik air minum, kepemilikan jamban dan kebiasaan cuci tangan dengan stunting.

Berdasarkan Tabel 1, usia ibu, pada kedua kelompok, kasus dan kontrol didominasi dengan ibu berusia $20-40$ tahun (31\% dan 30\%). Kelompok usia ini dapat dikategorikan menjadi dewasa awal, dimana banyak terjadi perubahan mulai dari aspek psikologis maupun psikososialnya. Pada masa ini seseorang akan berubah dari mencari pengetahuan menjadi menerapkan pengetahuan, misalnya mengejar karir dan membentuk keluarga ${ }^{21}$.

Berdasarkan usia balita, kelompok kasus didominasi balita dengan rentang usia $24-36$ bulan yaitu sebesar $66,7 \%$, sedangkan pada kelompok kontrol balita tersebar pada dua kategori usia yaitu pada rentang usia $24-36$ bulan dan rentang usia $37-48$ bulan dimana keduanya sama besar yaitu $39,4 \%$.

Tabel 1. Distribusi Usia Ibu, Usia Balita dan Jenis Kelamin Balita di Wilayah Kerja Puskesmas Kotakulon, Kabupaten Bondowoso Tahun 2018

\begin{tabular}{lcccc}
\hline \multirow{2}{*}{ Variabel } & \multicolumn{3}{c}{ Kasus } & \multicolumn{2}{c}{ Kontrol } \\
\cline { 2 - 5 } & $\mathbf{n}$ & $\%$ & $\mathbf{n}$ & $\%$ \\
\hline Usia Ibu & & & & \\
$20-40$ tahun & 31 & 93,9 & 30 & 90,9 \\
41-60 tahun & 2 & 6,1 & 3 & 9,1 \\
\hline Usia Balita & & & & \\
24-36 bulan & 22 & 66,7 & 13 & 39,4 \\
37-48 bulan & 6 & 18,2 & 13 & 39,4 \\
$49-59$ bulan & 5 & 15,1 & 7 & 21,2 \\
\hline Jenis Kelamin Balita & & & & \\
Laki- laki & 14 & 42,4 & 23 & 69,7 \\
Perempuan & 19 & 57,6 & 10 & 30,3 \\
\hline
\end{tabular}

Balita dikategorikan menjadi kelompok yang rentan mengalami masalah gizi karena pertumbuhan dan perkembangan pada masa balita melaju sangat pesat, sehingga apabila kurang maksimal dalam pemenuhan gizinya maka akan berdampak pada kehidupan selanjutnya. Begitu juga dengan masalah stunting, kekurangan gizi yang dialami saat janin dan awal setelah bayi lahir akan mempengaruhi pertumbuhan dan perkembangan balita karena kondisi stunting baru akan terlihat setelah anak berusia dua tahun ${ }^{22}$.

Berdasarkan jenis kelamin balita, kelompok kasus terdiri dari balita perempuan yang lebih dominan daripada balita laki - laki yaitu $57,6 \%$, sementara itu kelompok kontrol didominasi oleh balita laki - laki yaitu $69,7 \%$.

Tabel 2. Frekuensi Sumber Air Minum di Wilayah Kerja Puskesmas Kotakulon Kabupaten Bondowoso

\begin{tabular}{lcccc}
\hline \multirow{2}{*}{ Sumber air minum } & \multicolumn{2}{c}{ Kasus } & \multicolumn{2}{c}{ Kontrol } \\
\cline { 2 - 5 } & $\mathbf{n}$ & $\boldsymbol{\%}$ & $\mathbf{n}$ & $\%$ \\
\hline PDAM & 2 & 6 & 6 & 18,2 \\
Air mineral dalam kemasan & 6 & 18,2 & 5 & 15,1 \\
Sungai & 0 & 0 & 0 & 0 \\
Sumur & 25 & 75,8 & 22 & 66,7 \\
Penampungan air hujan (PAH) & 0 & 0 & 0 & 0 \\
\hline
\end{tabular}

Berdasarkan Tabel 2, sumber air minum kelompok kasus dan kontrol didominasi air yang berasal dari sumur yaitu sebanyak 25 responden pada kelompok kasus dan 22 responden pada kelompok kontrol. Sumber air minum yang tergolong air terlindung adalah yang berasal dari PDAM dan air mineral dalam kemasan/air isi ulang, sedangkan air tidak terlindung adalah air yang berasal dari sungai, sumur dan penampungan air hujan. Air yang tidak terlindung dapat mempengaruhi 
kesehatan salah satunya adalah penyakit diare, dimana penyakit diare berkontribusi besar pada kasus kematian balita. Diare yang terjadi pada balita juga dapat menghalangi balita untuk mencapai potensi pertumbuhan mereka ${ }^{23}$.

Berdasarkan Tabel 3, faktor terbesar yang menyebabkan kualitas fisik air minum responden pada kedua kelompok tidak memenuhi syarat adalah air minum yang berbau. Pada kelompok kasus ditemukan sebanyak $63,6 \%$ kualitas fisik air minum responden berbau dan pada kelompok kontrol ditemukan sebanyak $60,6 \%$ kualitas air minum responden yang berbau. Berdasarkan observasi peneliti, air minum tersebut memiliki bau seperti bau tanah, asap, dan atau besi. Hal ini menyebabkan kualitas fisik air minum tidak memenuhi syarat yang ditetapkan oleh Menteri Kesehatan RI bahwa kualitas air minum yang baik adalah tidak keruh, tidak berwarna, tidak berbau dan tidak berasa ${ }^{14}$.

Berdasarkan Tabel 3, faktor terbesar yang menyebabkan kualitas fisik air minum responden pada kedua kelompok tidak memenuhi syarat adalah air minum yang berbau. Pada kelompok kasus ditemukan sebanyak $63,6 \%$ kualitas fisik air minum responden berbau dan pada kelompok kontrol ditemukan sebanyak $60,6 \%$ kualitas air minum responden yang berbau. Berdasarkan observasi peneliti, air minum tersebut

memiliki bau seperti bau tanah, asap, dan atau besi. Hal ini menyebabkan kualitas fisik air minum tidak memenuhi syarat yang ditetapkan oleh Menteri Kesehatan RI bahwa kualitas air minum yang baik adalah tidak keruh, tidak berwarna, tidak berbau dan tidak berasa $^{14}$
Pada variabel kepemilikan jamban, ditemukan bahwa jamban masyarakat di wilayah kerja Puskesmas Kotakulon Kabupaten Bondowoso banyak yang tidak sesuai prasyarat jamban sehat utamanya pada konstruksi saluran pembuangan limbah. Sebanyak $60,6 \%$ responden pada kelompok kasus tidak memiliki tangki septik atau cubluk, sedangkan pada kelompok kontrol sebanyak $42,4 \%$ responden yang tidak memiliki penampungan limbah dari jamban ini. Berdasarkan hasil wawancara, limbah dari jamban tersebut langsung dialirkan ke sungai terdekat. Tidak tersedianya tangki septik ini berhubungan dengan biaya pembangunan jamban sehat yang cukup tinggi sehingga masyarakat lebih memilih untuk tidak memperbaiki/mengubah konstruksi jamban sesuai dengan syarat bangunan jamban yang diatur dalam Peraturan Menteri Kesehatan Nomor 3 Tahun 2014 tentang Sanitasi Total Berbasis Masyarakat. Padahal, jamban sehat atau sarana pembuangan feses efektif untuk menghentikan mata rantai penyebaran penyakit ${ }^{16}$.

Berdasarkan Tabel 3, rata - rata yang menyebabkan kebiasaan cuci tangan responden menjadi kurang baik pada kelompok kasus adalah tidak mencuci tangan setelah kontak dengan hewan. Sebanyak $73 \%$ responden pada kelompok kasus tidak mencuci tangan setelah kontak dengan hewan dan atau hanya mencuci tangan dengan air, padahal hewan dapat membawa risiko penyakit infeksi, terlebih lagi kuman atau mikroorganisme yang dibawa hewan tidak dapat dilihat dengan mata telanjang ${ }^{24}$. Pada kelompok kontrol, hal yang menyebabkan kebiasaan cuci tangan rata - rata responden menjadi tidak baik adalah tidak mencuci tangan dengan sabun setelah buang air kecil. Ditemukan sebanyak $63,6 \%$ responden pada kelompok kontrol tidak

Tabel 3. Frekuensi Kualitas Fisik Air Minum, Kepemilikan Jamban dan Kebiasaan Cuci Tangan di Wilayah Kerja Puskesmas Kotakulon Kabupaten Bondowoso Tahun 2018

\begin{tabular}{|c|c|c|c|c|}
\hline \multirow{2}{*}{ Variabel } & \multicolumn{2}{|c|}{ Kasus } & \multicolumn{2}{|c|}{ Kontrol } \\
\hline & Ya & Tidak & Ya & Tidak \\
\hline \multicolumn{5}{|l|}{ Kualitas fisik air minum } \\
\hline Keruh & 0 & 33 (100\%) & 0 & 33 (100\%) \\
\hline Berwarna & 0 & $33(100 \%)$ & 0 & $33(100 \%)$ \\
\hline Berbau & $21(63,6 \%)$ & $12(36,4 \%)$ & $20(60,6 \%)$ & $13(39,4 \%)$ \\
\hline Berasa & $20(60,6 \%)$ & $13(39,4 \%)$ & $18(54,5 \%)$ & $15(45,5 \%)$ \\
\hline \multicolumn{5}{|l|}{ Kepemilikan jamban } \\
\hline Memiliki jamban keluarga & $31(93,9 \%)$ & $2(6,1 \%)$ & 32 (97\%) & $1(3 \%)$ \\
\hline $\begin{array}{l}\text { Penghuni rumah termasuk balita menggunakan jamban } \\
\text { keluarga }\end{array}$ & $31(93,9 \%)$ & $2(6,1 \%)$ & $32(97 \%)$ & $1(3 \%)$ \\
\hline Bangunan atas jamban tertutup & $33(100 \%)$ & 0 & $32(97 \%)$ & $1(3 \%)$ \\
\hline Terdapat konstruksi leher angsa & $33(100 \%)$ & 0 & $32(97 \%)$ & $1(3 \%)$ \\
\hline Terdapat saluran pembuangan limbah & $31(93,9 \%)$ & $2(6,1 \%)$ & $32(97 \%)$ & $1(3 \%)$ \\
\hline Terdapat tangki septik atau cubluk & $13(39,4 \%)$ & $20(60,6 \%)$ & $19(57,6 \%)$ & $14(42,4 \%)$ \\
\hline \multicolumn{5}{|l|}{ Kebiasaan cuci tangan } \\
\hline Cuci tangan menggunakan air mengalir & $33(100 \%)$ & 0 & $33(100 \%)$ & 0 \\
\hline Cuci tangan menggunakan sabun & $33(100 \%)$ & 0 & $33(100 \%)$ & 0 \\
\hline Cuci tangan sebelum makan & $33(100 \%)$ & 0 & $33(100 \%)$ & 0 \\
\hline $\begin{array}{l}\text { Cuci tangan sebelum mengolah dan menghidangkan } \\
\text { makanan }\end{array}$ & $33(100 \%)$ & 0 & $33(100 \%)$ & 0 \\
\hline Cuci tangan sebelum menyusui & $30(91 \%)$ & $3(9 \%)$ & $33(100 \%)$ & 0 \\
\hline Cuci tangan sebelum memberi makan bayi/balita & $30(91 \%)$ & $3(9 \%)$ & $27(81,8 \%)$ & $6(18,2 \%)$ \\
\hline Cuci tangan sehabis buang air besar/kecil & $16(48,5 \%)$ & $17(52,5 \%)$ & $12(36,4 \%)$ & $21(63,6 \%)$ \\
\hline Cuci tangan setelah kontak dengan hewan & $9(27 \%)$ & $24(73 \%)$ & $29(87,9 \%)$ & $4(12,1 \%)$ \\
\hline
\end{tabular}


mencuci tangan menggunakan sabun setelah buang air kecil.Sebagian besar masyarakat memiliki pendapat bahwa apabila tagan sudah dibasuh dengan air maka tangan sudah bersih, padahal tanpa sabun, bakteri dan kuman penyebab penyakit masih menempel pada tangan yang dapat masuk ke dalam tubuh bersamaan dengan makanan yang dikonsumsi. Mencuci tangan dengan sabun dan air mengalir lebih efektif dalam membersihkan kuman ${ }^{25}$.

Berdasarkan Tabel 4, sebesar 75,8\% sumber air minum responden pada kelompok kasus yang masuk dalam kategori tidak terlindung, sedangkan pada kelompok kontrol terdapat $66,7 \%$ sumber air minum responden yang tidak terlindung. Lebih tinggi $9,1 \%$ balita pada kelompok kasus yang menggunakan sumber air minum tidak terlindung daripada kelompok kontrol, dimana air ini bersumber dari air sumur. Hasil uji chisquare menunjukkan tidak ada hubungan yang bermakna antara sumber air minum dengan kejadian stunting di wilayah kerja Puskesmas Kotakulon Kabupaten Bondowoso dengan nilai p-value 0,415. Faktor stunting bisa terjadi melalui banyak sebab, sehingga dalam studi ini sumber air minum bukan merupakan faktor kejadian stunting. Selain itu persentase sumber air minum tidak terlindung kedua kelompok sama - sama tinggi sehingga tidak ditemukan perbedaan yang bermakna. Temuan ini berbanding terbalik dengan studi studi yang dilakukan di Sumatera yang mengatakan bahwa balita yang berasal dari keluarga dengan akses sumber air minum tidak terlindung memiliki risiko 1,35 kali untuk mengalami stunting ${ }^{13}$.

Berdasarkan Tabel 4, sebesar $75,8 \%$ sumber air minum responden pada kelompok kasus yang masuk dalam kategori tidak terlindung, sedangkan pada kelompok kontrol terdapat $66,7 \%$ sumber air minum responden yang tidak terlindung. Lebih tinggi $9,1 \%$ balita pada kelompok kasus yang menggunakan sumber air minum tidak terlindung daripada kelompok kontrol, dimana air ini bersumber dari air sumur. Hasil uji chisquare menunjukkan tidak ada hubungan yang bermakna antara sumber air minum dengan kejadian stunting di wilayah kerja Puskesmas Kotakulon Kabupaten Bondowoso dengan nilai p-value 0,415. Faktor stunting bisa terjadi melalui banyak sebab, sehingga dalam studi ini sumber air minum bukan merupakan faktor kejadian stunting. Selain itu persentase sumber air minum tidak terlindung kedua kelompok sama - sama tinggi sehingga tidak ditemukan perbedaan yang bermakna. Temuan ini berbanding terbalik dengan studi studi yang dilakukan di Sumatera yang mengatakan bahwa balita yang berasal dari keluarga dengan akses sumber air minum tidak terlindung memiliki risiko 1,35 kali untuk mengalami stunting ${ }^{13}$.

Pada kelompok kasus, sebesar $75,8 \%$ kualitas fisik air minum responden yang tidak memenuhi syarat dan pada kelompok kontrol sebesar $69,7 \%$ responden yang kualitas fisik air minumnya tidak memenuhi syarat. Kualitas fisik air minum yang tidak memenuhi syarat pada kelompok kasus memiliki kecenderungan lebih tinggi 6,1\% daripada kelompok kontrol. Akan tetapi, dari hasil uji didapatkan nilai $p$-value 0,58 yang berarti tidak ada hubungan kualitas fisik air minum dengan stunting. Penyebabnya adalah kualitas fisik air minum yang tidak memenuhi syarat kedua kelompok sama - sama tinggi. Hasil ini serupa dengan sebuah penelitian di India yang mengungkapkan bahwa peningkatan kualitas air minum tidak memiliki hubungan yang signifikan terhadap pertumbuhan anak usia dini ${ }^{26}$.

Berdasarkan variabel kepemilikan jamban, terdapat $60,6 \%$ responden pada kelompok kasus yang tidak memiliki jamban sehat, dan $45,5 \%$ responden yang memiliki jamban sehat. Kelompok kasus yang tidak memiliki jamban sehat lebih tinggi sebesar $15,11 \%$ responden dibandingkan dengan kelompok kontrol. Nilai p-value 0,22 didapatkan melalui uji chi-square dan menunjukkan bahwa tidak terdapat hubungan antara kepemilikan jamban dengan stunting dalam penelitian ini. Hal ini serupa dengan hasil temuan di Kabupaten Minahasa Utara yang menyatakan bahwa tidak ada hubungan yang signifikan antara kepemilikan jamban dengan status gizi PB/U anak usia $0-23$ bulan di Pulau Nain Kecamatan Nori27.

Tabel 4. Hubungan WASH dengan Kejadian Stunting di Wilayah Kerja Puskesmas Kotakulon Kabupaten Bondowoso Tahun 2018

\begin{tabular}{|c|c|c|c|c|c|c|}
\hline \multirow{2}{*}{ Variabel } & \multicolumn{2}{|c|}{ Kasus } & \multicolumn{2}{|c|}{ Kontrol } & \multirow{2}{*}{$p$ value } & \multirow{2}{*}{ OR } \\
\hline & $\mathbf{n}$ & $\%$ & $\mathbf{n}$ & $\%$ & & \\
\hline \multicolumn{7}{|l|}{ Sumber air minum } \\
\hline Terlindung & 8 & 24,2 & 11 & 33,3 & \multirow{2}{*}{0,415} & \multirow{2}{*}{0,64} \\
\hline Tidak terlindung & 25 & 75,8 & 22 & 66,7 & & \\
\hline \multicolumn{7}{|l|}{ Kualitas Fisik Air Minum } \\
\hline Memenuhi syarat & 8 & 24,2 & 10 & 30,3 & \multirow{2}{*}{0,58} & \multirow{2}{*}{0,74} \\
\hline Tidak memenuhi syarat & 25 & 75,8 & 23 & 69,7 & & \\
\hline \multicolumn{7}{|l|}{ Kepemilikan Jamban } \\
\hline Memiliki jamban sehat & 13 & 39,4 & 18 & 54,5 & \multirow{2}{*}{0,22} & \multirow{2}{*}{0,54} \\
\hline Tidak memiliki jamban sehat & 20 & 60,6 & 15 & 45,5 & & \\
\hline \multicolumn{7}{|l|}{ Kebiasaan Cuci Tangan } \\
\hline Baik & 4 & 12,1 & 18 & 54,5 & \multirow{2}{*}{$<0,001$} & \multirow{2}{*}{0,12} \\
\hline Kurang baik & 29 & 87,9 & 15 & 45,5 & & \\
\hline
\end{tabular}


Hasil penelitian menunjukkan terdapat $87,9 \%$ responden yang kebiasaan cuci tangannya kurang baik pada kelompok kasus sedangkan terdapat 45,5\% responden pada kelompok kontrol yang kebiasaan cuci tangannya kurang baik. Proporsi kelompok kasus lebih tinggi $42,4 \%$ responden yang kebiasaan cuci tangannya masih kurang baik daripada kelompok kontrol. Hasil uji chi-square menunjukkan nilai $p$-value kebiasaan cuci tangan terhadap kejadian stunting adalah 0,000. Hal ini menunjukkan bahwa ada hubungan antara kebiasaan cuci tangan dengan kejadian stunting di wilayah kerja Puskesmas Kotakulon Kabupaten Bondowoso. Responden dengan kebiasaan cuci tangan yang kurang baik memiliki risiko 0,12 kali balitanya mengalami stunting.

Hal ini disebabkan karena kebiasaan cuci tangan berpengaruh terhadap kebersihan diri pengasuh balita yaitu ibu dimana ibu selalu berinteraksi dengan balitanya. Menurut observasi penelilti yang disajikan dalam tabel 3 , faktor yang paling mempengaruhi adalah responden tidak mencuci tangan setelah kontak dengan hewan. Hewan dapat dengan mudah dan cepat dalam menyebarkan penyakit pada manusia yaitu melalui feses, bulu, dan kulit, serta lingkungan sekitar dimana hewan itu tinggal. Walaupun hewan terlihat sehat dan bersih, namun kuman yang tidak dapat dliihat bisa menular pada manusia maupun hewan lain. Salah satu bakteri dari hewan yang dapat menjangkit hewan dan menyebar pada manusia adalah E. coli 0157, dimana bakteri ini berada dalam sistem pencernaan hewan.

Setelah dikeluarkan melalui feses, bakteri ini dapat menyebar pada anggota tubuh hewan. E. coli O157 dapat menyebabkan diare berair bahkan berdarah, demam, mual, dan muntah yang terjadi 3 atau 4 hari setelah seseorang kontak dengan bakteri ini $^{28}$. Penyebaran bakteri ini dapat dicegah dengan mencuci tangan menggunakan sabun dan air mengalir setelah kontak dengan hewan. Penelitian sebelumnya yang dilakukan di Armenia mendapatkan hasil yang sama bahwa praktik kebiasaan cuci tangan yang buruk merupakan faktor risiko terjadinya stunting di daerah pedesaan tersebut ${ }^{29}$. Hasil penelitian di wilayah kerja sebuah puskesmas di Surakarta juga mengungkapkan bahwa perilaku PHBS (Perilaku Hidup Bersih dan Sehat) dimana salah satu indikatornya adalah cuci tangan dengan sabun dan air bersih berpengaruh pada derajat kesehatan dan status gizi keluarga ${ }^{30}$.

\section{KESIMPULAN}

Berdasarkan faktor WASH (water, sanitation and hygiene) tidak terdapat hubungan antara sumber air minum, kualitas fisik air minum, dan kepemilikan jamban dengan kejadian stunting diwilayah kerja Puskesmas Kotakulon Kabupaten Bondowoso, namun ada hubungan yang bermakna antara kebiasaan cuci tangan dengan kejadian stunting. Cuci tangan yang kurang baik pada ibu memiliki risiko stunting pada balitanya sebesar 0,12 kali lebih tinggi.

\section{ACKNOWLEDGEMENT}

Peneliti mengucapkan terima kasih kepada seluruh bidan, petugas gizi, dan kader di wilayah kerja Puskesmas Kotakulon, Kabupaten Bondowoso yang telah membantu proses penelitian hingga penelitian ini selesai dengan lancar. Peneliti juga mengucapkan terima kasih kepada balita dan ibu balita yang telah ikut serta dalam penelitian ini.

\section{REFERENS|}

1. Kemenkes RI. Kemenkes No.1995/Menkes/SK/XII/2010 tentang Standar Antropometri Penilaian Status Gizi Anak. 40 (2010). doi:10.1016/j.eneco.2014.11.003

2. Kementrian Kesehatan RI. Situasi balita pendek. Info Datin 2442-7659 (2016). doi:ISSN 24427659

3. Kemiskinan, T. N. P. P. 100 Kabupaten/kota prioritas untuk intervensi anak kerdil (stunting). 1, (2017).

4. Kementerian Kesehatan Republik Indonesia. Buku Saku Pemantauan Status Gizi dan Indikator Kinerja Gizi Tahun 2015. 242 (2015). doi:17 November 2016

5. Kementerian Kesehatan Republik Indonesia. Hasil Pemantauan Status Gizi (PSG) dan Penjelasannya Tahun 2016. (2016).

6. Kementerian Kesehatan Republik Indonesia. Buku Saku Pemantauan Status Gizi Tahun 2017. 140 (2017). doi:10.3870/tzzz.2010.07.001

7. United Nations Children's Fun. Approach to Nutrition Programming for the East Asia-Pacific Region. 3, (2014).

8. Uliyanti, Tamtomo, D. G. \& Anantanyu, S. Faktor Yang Berhubungan Dengan Kejadian Stunting Pada Balita Usia 24-59 Bulan. J. Vokasi Kesehat. 3, 1-11 (2017).

9. Nasrul, Hafid, F., Thaha, A. R. \& Suriah. Faktor Risiko Stunting Usia 6-23 Bulan di Kecamatan Bontoramba Kabupaten Jeneponto. Media Kesehat. Masy. Indones. 11, 139-146 (2015).

10. Prüss-Üstün, A., Bos, R., Gore, F. \& Bartram, J. Safer Water, Better Health. WHO Library Cataloguing-in-Publication Data (2008).

11. Bondowoso, D. K. Profil Kesehatan Kabupaten Bondowoso Tahun 2016. (2016).

12. Bondowoso, D. K. Profil Kesehatan Tahun 2017 Kabupaten Bondowoso. (2017).

13. Oktarina, Z. \& Sudiarti, T. Faktor Risiko Stunting pada Balita (24-59 Bulan) di Sumatera. J. Gizi dan Pangan 8, 175-180 (2013).

14. Kementerian Kesehatan. Peraturan Menteri Kesehatan Republik IndoKementerian Kesehatan (2010) Peraturan Menteri Kesehatan Republik Indonesia Nomor 492/Menkes/Per/IV/2010, Peraturan Mentri Kesehatan Republik Indonesia.nesia NOMOR 492/MENKES/PER/IV/2010. Peraturan Mentri Kesehatan Republik Indonesia MENKES (2010). 
15. Sukoco, N. E. W., Pambudi, J. \& Herawati, M. H. Hubungan status gizi anak balita dengan orang tua bekerja. Bul. Penelit. Sist. Kesehat. 18, 387397 (2015).

16. Kementerian Kesehatan Republik Indonesia. Sanitasi Total Berbasis Masyarakat. (2014).

17. Rohmah, N. \& Syahrul, F. Hubungan Kebiasaan Cuci Tangan dan Penggunaan Jamban Sehat dengan Kejdian Diare Balita. J. Berk. Epidemiol. 5, 95-106 (2017).

18. Kementerian Kesehatan Republik Indonesia. Perilaku Mencuci Tangan Pakai Sabun di Indonesia. (2014).

19. Umiati. Hubungan Antara Sanitasi Lingkungan dengan Kejadian Diare Pada Balita di Wilayah Kerja Puskesmas Nogosari Kabupaten Boyolali Tahun 2009. (Universitas Mihammadiyah Surakarta, 2010).

20. Sari, M. H. Hubungan Perilaku Cuci Tangan dengan Kejadian Diare Pada Balita di Posyandu Dusun Nglebeng Tamanan Banguntapan Bantul. (Universitas Aisyiyah Yogyakarta, 2017).

21. Adriani, M. \& Wirjatmadi, B. Peranan Gizi dalam Siklus Kehidupan. (Kencana Prenadamedia Group, 2012).

22. Sutarto, Mayasari, D. \& Indriyani, R. Stunting , Faktor Resiko dan Pencegahannya. J. Agromedicine 5, 540-545 (2018).

23. INDONESIA, U. Air Bersih, Sanitasi \& Kebersihan. Ringkasan Kajian 1-6 (2012).

24. England, P. H. Infection risk at petting farms: PHE urges good hand hygiene. GOV.UK (2015). Available at: https://www.gov.uk/government/news/infectio n-risk-at-petting-farms-phe-urges-good-handhygiene.

25. Prevention, C. for D. C. and. Show Me the Science - Why Wash Your Hands? Cdc 1 (2018). Available at: https://www.cdc.gov/handwashing/whyhandwashing.html.

26. Johri, M., Sylvestre, M.-P., Koné, G. K., Chandra, D. \& Subramanian, S. V. Effects of improved drinking water quality on early childhood growth in rural Uttar Pradesh, India: A propensity-score analysis. PLoS One 14, 1-16 (2019).

27. Rondonuwu, S., Punuh, M. I. \& Ratag, B. T. Hubungan Antara Riwayat Penyakit Infeksi, Ketersediaan Air Bersih Dan Kepemilikan Jamban Dengan Status Gizi Pada Anak Usia 6-24 Bulan Di Pulau Nain Kecamatan Wori Kabupaten Minahasa Utara. Media Kesehat. 8, (2016).

28. National Center for Emerging and Zoonotic Infectious Diseases, C. for D. C. and P. E. coli Infection. (2019). Available at: https://www.cdc.gov/healthypets/diseases/ecoli .html.

29. Demirchyan, A. \& Petrosyan, V. Hand hygiene predicts stunting among rural children in Armenia. Eur. J. Public Health 27, (2017).

30. Apriani, L. Hubungan Karakteristik Ibu, Pelaksanaan Keluarga Sadar Gizi (Kadarzi) Dan Perilaku Hidup Bersih Sehat (Phbs) Dengan Kejadian Stunting (Studi kasus pada baduta 6-23 bulan di Wilayah Kerja Puskesmas Pucang Sawit Kota Surakarta). J. Kesehat. Masy. 6, 198-205 (2018). 